Military Technical College Cairo, Egypt

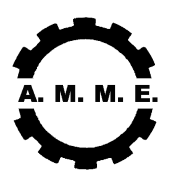

$12^{\text {th }}$ International Conference

on Applied Mechanics and

Mechanical Engineering (AMME)

\title{
EXPLORATORY STUDY OF THE BEHAVIOR OF SOME LOCAL AGRICULTURAL RESIDUAL MATERIALS TO BE USED FOR REINFORCING CONSTRUCTION MATERIALS
}

\author{
Sharkawi A.M. * and Showaib E.A. **
}

\begin{abstract}
Although, many agricultural residues had been used in construction applications of the mankind history, but today most of them have became an overburden. Accordingly, burning of their accumulation has become annual habit causing environmental problem combined with the economical losses. Using agricultural residues, with suitable tensile strength, as reinforcing materials for construction materials had shown promising results in literature. In this research an exploratory study is implemented to investigate the physical and mechanical properties of some local materials to be used as reinforced elements for construction materials. As promising natural materials for reinforcing application, some parts of palm trees (e.g. ribs) and water reed stems are chosen for this study. The effect of some limited exposure conditions and protection techniques are also investigated on the tensile behavior of the selected natural materials. The explored materials show promising tensile behavior to be used for reinforcing applications but with low stiffness and durability. Although protection techniques, used in this research, are effective to solve the problem of durability and slippage in the short term, long term tensile behavior of the explored residues need to be studied.
\end{abstract}

\footnotetext{
* Assistant Professor, Structural Engineering Department, Faculty of Engineering, Tanta University

** Assistant Professor, Mechanical Engineering Department, Faculty of Engineering, Tanta University
} 


\section{INTRODUCTION}

With the industrial revolution, a tremendous shift occurred in the social life with a decrease in the dependence on agriculturalmaterials in the construction field among many other applications. The applications in construction deal -mainly- today with steel and concrete and to a lesser extent with different types of bricks and dimension stones with a clear negligence of agricultural material resources.

Today, with the less dependence on agricultural residual materials, in industrial fields, a huge accumulation of agricultural residue has become an annual problem allover the world especially for the farmers who need to clear their fields for the cultivation of the next crop. Locally, burning residues becomes a common practice in the Egyptian village as the fastest way for getting rid of unused agricultural residue materials. This practice is abusing both the environment and the additive value of millions tons of annual agricultural residues. Many development countries studied different ideas for recycling these agricultural residues to be used in various fields such as animal-feeding applications, paper and rural bio-energy. On the other hand, using the appropriate of these materials in construction applications have been explored widely. As an example, using fly ash, made for rice husk, after controlled burning, showed promising results as cement replacement.

Using some promising agricultural residues, as reinforcing materials, was traditionally applied in many development countries based on the experience.

However, studying the behavior, of these materials started in the twenties of the past centuries, while the main effort toward the neat description of the behavior (i.e. mechanical and physical) for some of these materials began in the late 1960s. Toward reliable applications, the main properties for some types of agricultural residues had been presented in literature as prospective reinforcing materials.

The main properties of some natural fibers -as reinforcing material- are fairly known in literature. Table (1) and Fig (1) present some main physical and mechanical properties and typical stress-strain curves under tension respectively, for some agricultural materials.

Table 1. Properties of some natural reinforcing materials ${ }^{(10)}$

\begin{tabular}{|c|c|c|c|c|c|}
\hline \multirow[b]{2}{*}{ 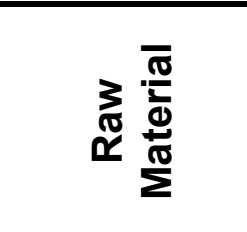 } & \multicolumn{2}{|c|}{ Physical Properties } & \multicolumn{3}{|c|}{ Mechanical Properties } \\
\hline & 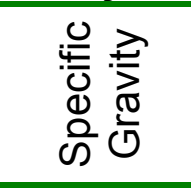 & 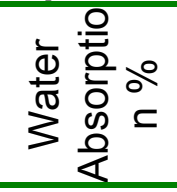 & 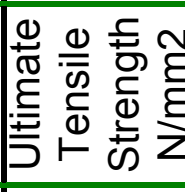 & 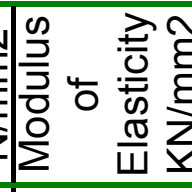 & 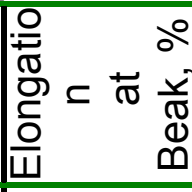 \\
\hline Coconut coir & $1.12-1.15$ & $130-180$ & $\begin{array}{l}120- \\
200\end{array}$ & $19-26$ & $10-25$ \\
\hline Sisal & ------- & $60-70$ & $\begin{array}{c}280- \\
568\end{array}$ & $13-26$ & $3-5$ \\
\hline Jute & $1.02-1.04$ & ----- & $\begin{array}{c}250- \\
350\end{array}$ & $26-32$ & $1.5-1.9$ \\
\hline Bamboo & 1.52 & $30-65$ & $\begin{array}{c}240- \\
442\end{array}$ & $20-34$ & $6-13$ \\
\hline
\end{tabular}




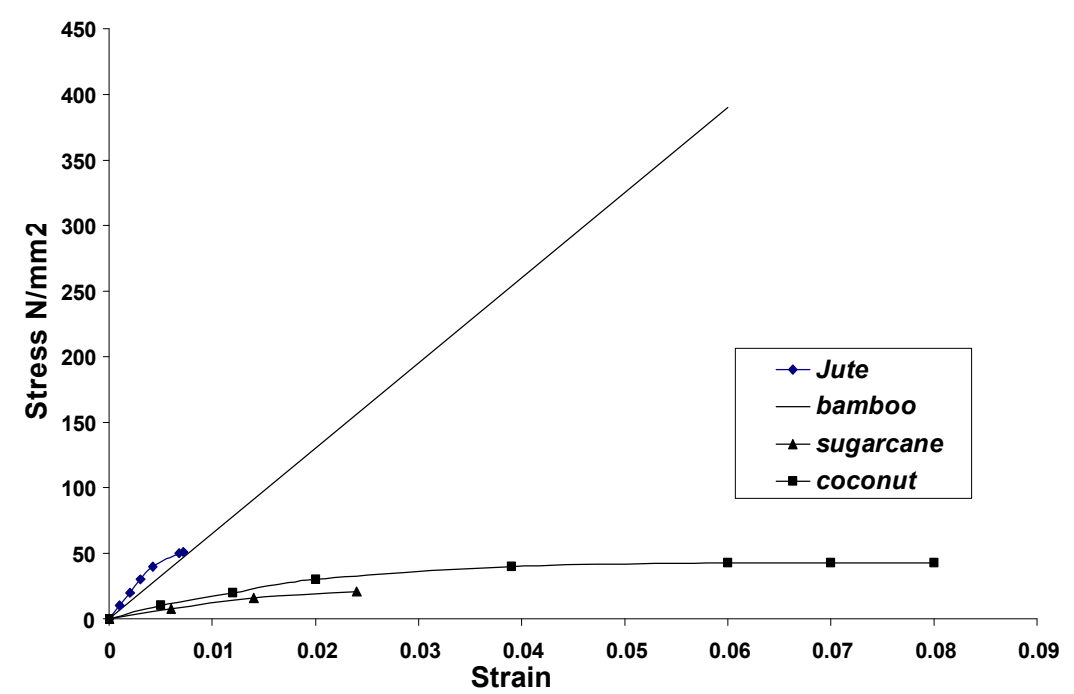

Fig. 1 typical stress-strain relation of some natural reinforcing materials in tension ${ }^{(10)}$

Locally, in the late sixties of the past century Youssef ${ }^{(12)}$ carried out an research work in which the main physical and mechanical prosperities of reinforcing bars extracted from a locally cultivated bamboo and date palm midribs were investigated. In addition the effect of some types of water repellent treatment methods were also studied to solve the problem of such natural material high water absorption and the corresponding bonding loss between the rebars and concrete. The mechanical properties of these natural rebars varied considerably between the individual samples, along the sample length and with the change of the sample moisture water content (green vs. seasoned). However, the ultimate tensile strength of seasoned locally grown bamboo culms ranged between 192Mpa at nodes and 261Mpa between nodes. While the ultimate tensile strength of the seasoned locally grown date palm midribs ranged between 123Mpa for the distal parts of the rib and $145 \mathrm{Mpa}$ for the basal parts. On the other hand, the modulus of elasticity of both rebar type are closer to concrete than to steel.

Recently, Al-Ashker et al ${ }^{(1)}$ had studied some physical properties (density and water absorption) and some mechanical properties (tensile strength and tensile modulus of elasticity) of whole stem of the date cluster. The average ultimate tensile strength and tensile modulus of elasticity of the dry samples are $78 \mathrm{Mpa}$ and $15 \mathrm{Gpa}$ receptively. While the tensile strength of soaked samples in tap water and saturated lime solution are $127 \mathrm{Mpa}$ and $80 \mathrm{Mpa}$ respectively.

On the other hand, to use the recycled date palm midribs for particleboard production (4), (5), (6) the tensile strength for both the outer and inner layers of palm midribs had been investigated. Table (2) presents the values of the tensile strength for both the outer and inner layers of palm midribs and their specific tensile strength compared to other wood spices and steel.37. 
Table 2. The values of tensile strength and specific tensile strength for DPLM inner and outer layers, compared with several wood species and steel ${ }^{(6)}$

\begin{tabular}{|l|c|c|}
\hline \multicolumn{1}{|c|}{ Material } & $\begin{array}{c}\text { Tensile strength } \\
\left(\mathbf{N} / \mathbf{m m}^{\mathbf{2}}\right)\end{array}$ & $\begin{array}{c}\text { Specific tensile } \\
\text { strength } \\
\left(\mathbf{N} / \mathbf{m m}^{\mathbf{2}}\right) /(\mathbf{g} / \mathbf{c m} \mathbf{3})\end{array}$ \\
\hline Outer layer & 248 & 196 \\
Inner layer & 70 & 86 \\
European red & 78 & 142 \\
pine & 97 & 140 \\
Beech & 367 & 46 \\
Steel 37 & & \\
\hline
\end{tabular}

Physical and mechanical properties of these agricultural materials are dependable on the local conditions such as cultivation, age and exposure conditions. Accordingly, the same natural material (e.g. bamboo) may have different properties, depending on the cultivation region (9), (11). Though, for reliable application, a full functional specification for each type of the promising agricultural residues and for each particular application, need to be studied. A comprehensive study were proposed -by the authors- considering the main factors which affect the behavior of such agricultural reinforcing materials and to expect their average behavior ${ }^{(8)}$.

As a first step to implement this proposed program, a pilot study is required to explore the behavior of some promising local agricultural materials and examine their feasibility as reinforcing elements. In this research work, exploratory testing program is processed to investigate the main mechanical and physical properties of some local agricultural materials in their unprocessed (e.g. virgin) state and to highlight the possible effect of some exposure conditions and/or enhancement techniques on their behavior.

\section{RESEARCH SIGNIFICANCE}

Literature shows that many agricultural materials have promising behavior -as reinforcing elements- with low cost ${ }^{(2),(10)}$. However, limited information is available regarding the physical and mechanical properties of local agricultural materials in this application. On the other hand, there are tremendous factors affecting the behavior of such materials, which need to be considered to have reliable database of the behavior of such materials ${ }^{(8)}$. The following deficiencies have major concern in using such biomaterials in the application of reinforcing construction materials:

1- Their physical and mechanical properties have wide ranges due to various factors affecting agricultural material's behavior such as; their state (e.g. green vs. seasoned), existing of usual defects such as the existing of knots...etc.

2- The leak of durability due to degradation of such material in aggressive media (e.g. high alkalinity of concrete) and fermentation in water.

3- Low bond strength of these materials due to smooth surface of most of these materials beside their volumetric changes with the surrounding moist media (i.e. swelling with wetting and shrinkage with drying). 
Considering the aforementioned deficiencies and other relevant factors, a comprehensive testing program had been proposed by the authors ${ }^{(8)}$ to buildup a complete database for a reliable use of the local agricultural residues as reinforcing elements for construction materials. Beside the benefits of recycling these agricultural residues with environmental friendly manner, low cost construction materials can be provided for different local rural areas. Accordingly, properties of some local promising natural materials need to be explored in their average state. Average stated natural materials are simply the ready ones to be used in domestic application such as tools, furniture and mats (i.e. seasoned and visually sound). Because we have no other reliable evaluation tool, experts in such a domestic applications can determine the material's average condition.

In this research work, the main aim is to cover the following points ;

1- Explore the physical and mechanical properties -for tensile application- of unprocessed fibers and/or rebars extracted from local agricultural materials in their average state.

2- Highlight the role of material age (i.e. green vs. seasoned) on the tensile behavior of natural reinforcing rebars (NRR).

3- Examine the tensile behavior of some of these unprocessed agricultural materials after short-term (i.e. 2-month) exposure in conditions close to that expecting to be faced during their application such as water immersion and high alkalinity.

4- Investigate the influence of applying some enhancement techniques on the physical and mechanical behavior of some of the tested natural fibers and rebars such as;

- Protection coating to reduce the effect of the expecting swelling and degradation effects due to the exposure to water and aggressive high alkalinity respectively.

- End anchorage enhancement for rebars to fully utilize the use of the tensile strength of these rebars instead of the usual premature slippage failure.

\section{SCOPE OF WORK}

Generally, to have environmental and economical impact, selection of the tested agricultural residues is preferred to consider the materials having expected promising tensile behavior and which;

1- Have a problem of huge accumulation with a no clear alternative for recycling (e.g. has no nutrition value for animal feeding).

And /or

2- Use to be consumed in domestic applications (e.g. cleaning tools) and has been replaced by man-made material (e.g. plastics). 
Date palm tree is the first selected source to provide different kinds of reinforcing materials. Fig (2.a) shows the external structure of the common date palm tree, which is available in Egypt by over than 10 million trees. The Arabic pronunciation of each considered part is shown in fig (2.a) to be well recognized locally. Behavior of the following parts of the date palm tree structure is studied in this research work in their unprocessed (i.e. no special exposure conditions and enhancement techniques are applied), average state and their fibrous form:

1- Palm tree trunk coir fibers which pronounced in Arabic as "Kheash".

2- Palm tree ribs, which pronounced in Arabic as "greed", .considering the obvious difference between the inner and outer layers of the ribs as shown in fig ( 2 .b).

3- Palm tree leaves.

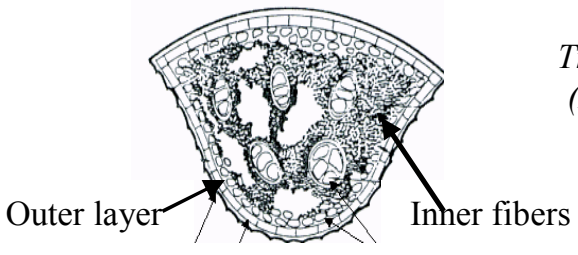

(b) Ribs cross-section (6)

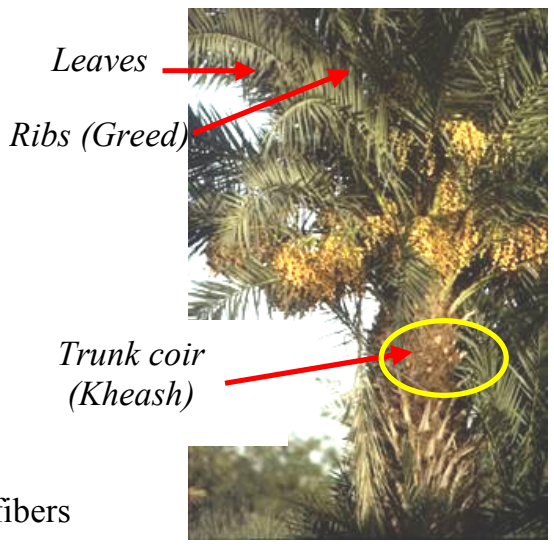

a) The studied palm tree parts

Fig. 2 The Investigated Parts of Palm Tree

Beside these materials, which related to date palm tree, behavior of narrow splits of water reed stem, which pronounced in Arabic as "Boose", is also explored.

In addition, behavior of agricultural materials in a form of reinforcing rebars is investigated. The chosen rebars are extracted from seasoned palm tree ribs "Greed" as whole (i.e. including the inner and outer fibers) and water reed stem "Boose"'.

The aforementioned explored materials are fulfilling conditions of selection. As an example, the mature palm tree produces about $50 \mathrm{~kg}$ of ribs "Greed" annually. Theses ribs, trunk coir fibers "Kheash" and leaves are usually used in domestic applications (e.g. cleaning tools) which have been replaced with plastics. On the other hand, burning of water reed stem "Boose" -which grows around water banks is a usual habit to get rid of their bushes.

In addition to considering the physical and tensile behaviors of seasoned averaged condition of these materials, special cases are also investigated which are: 


\section{i- $\quad$ For Fibers}

- Behavior of fibers extracted from palm tree trunk coir "Kheash" and inner fibers of palm tree ribs is explored after two-month period of immersion in water (case 1) and saturated solution of Calcium hydroxide (case 2). Both cases are applied on both unprocessed fibers and protected fibers with low cost epoxy, which is available locally (Kemapoxy 101 produced by CMB company). Theses cases are chosen to study the effect of short period exposure to concrete media.

\section{ii- For Rebars}

- Behavior of green palm tree ribs and water reed stem rebars are compared with the seasoned rebars to highlight the role of material age after cutting from the mother plant.

- Enhancement techniques for bond strength are implemented on palm tree ribs and water reed stem rebars using two different schemes of end anchorage to overcome the usual premature slippage failure.

Tables (3), (4) and (5) present the description of different specimen's types and conditions. For each of these materials, tensile test is applied beside the usual physical behavior tests. In addition to these tests, pullout tests, from concrete, are performed for rebar's samples.

Generally, for the expected variation of properties due to the cultivation conditions, this exploratory study is implemented on agricultural materials extracted from the same cultivation zone (i.e. Tanta city). The mechanical and physical properties are tested in -almost- the same period to avoid any effect of age on the relative properties (e.g. tensile strength with respect to the moisture content). However, their exposure history before testing is beyond the scope of this work.

\section{EXPERIMENTAL PROGRAM DESCRIPTION}

To determine the physical properties of each studied natural material, the standard tests for determining water absorption, moisture content and bulk specific gravity have been applied just before the tensile test. While tensile test on two different schemes of samples and accordingly two testing programs are performed. Individual extracted fibers or narrow splits are tested in limited capacity (i.e.5 KN) with high accuracy universal machine, while rebar samples are tested in another universal machine of higher capacity (i.e. $300 \mathrm{KN}$ ). Both universal machines are connected to two different data acquisition systems for recording load and displacement.

Due to the variation of sampling and testing setup of the aforementioned schemes, description of the experimental program of each scheme is presented separately in the following paragraphs. For such natural materials, sampling and testing process are described in details for their expected effects on the test results 
Table 3. Description of the explored natural fiber samples

\begin{tabular}{|c|c|c|c|c|c|}
\hline $\begin{array}{c}\text { Sampl } \\
\mathbf{e}\end{array}$ & A & B & C & D & E \\
\hline \hline ID & $\begin{array}{c}\text { Palm } \\
\text { Fiber } \\
\text { tree trunk } \\
\text { coir } \\
\text { "Kheash" }\end{array}$ & $\begin{array}{c}\text { Palm tree } \\
\text { inner fiber of } \\
\text { ribs "Greed" }\end{array}$ & $\begin{array}{c}\text { Palm tree } \\
\text { outer fiber of } \\
\text { ribs "Greed" }\end{array}$ & $\begin{array}{c}\text { Palm } \\
\text { tree } \\
\text { leaf }\end{array}$ & $\begin{array}{c}\text { Water } \\
\text { reed } \\
\text { stem } \\
\text { strips } \\
\text { "Boose" }\end{array}$ \\
\hline
\end{tabular}

Table 4. Description of exposure and protection conditions and related samples

\begin{tabular}{|c|c|c|c|c|c|c|c|c|c|c|}
\hline $\begin{array}{c}\text { Sample } \\
\text { ID }\end{array}$ & $\mathbf{A}_{\mathbf{1}}$ & $\mathbf{A}_{\mathbf{2}}$ & $\mathbf{A}_{\mathbf{3}}$ & $\mathbf{A}_{\mathbf{4}}$ & $\mathbf{A}_{\mathbf{5}}$ & $\mathbf{B}_{\mathbf{1}}$ & $\mathbf{B}_{\mathbf{2}}$ & $\mathbf{B}_{\mathbf{3}}$ & $\mathbf{B}_{\mathbf{4}}$ & $\mathbf{B}_{\mathbf{5}}$ \\
\hline $\begin{array}{c}\text { Fiber } \\
\text { Type }\end{array}$ & \multicolumn{3}{|c|}{ Palm tree trunk coir "Kheash" } & \multicolumn{3}{|c|}{ Palm tree inner fiber of ribs } \\
"Greed"
\end{tabular}

Table 5. Description of the explored natural rebar samples

\begin{tabular}{|c|c|c|c|c|}
\hline $\begin{array}{c}\text { Sampl } \\
\text { e } \\
\text { ID }\end{array}$ & Rebar's Origin & State & $\begin{array}{l}\text { Protection } \\
\text { Technique }\end{array}$ & $\begin{array}{c}\text { End } \\
\text { Anchorage } \\
\text { Enhancement } \\
\text { Technique }\end{array}$ \\
\hline Rs & $\begin{array}{c}\text { Whole Palm tree ribs } \\
\text { "Greed " }\end{array}$ & $\begin{array}{c}\text { Seasone } \\
d\end{array}$ & No & No \\
\hline Rsc & & $\begin{array}{c}\text { Seasone } \\
d\end{array}$ & $\begin{array}{l}\text { Epoxy } \\
\text { coated }\end{array}$ & No \\
\hline $\mathbf{R g}$ & “ & Green & No & No \\
\hline Rs1 & “ & $\begin{array}{l}\text { Seasone } \\
\mathrm{d}\end{array}$ & $\begin{array}{l}\text { Epoxy } \\
\text { coated }\end{array}$ & A \\
\hline Rs2 & " & $\begin{array}{c}\text { Seasone } \\
d\end{array}$ & $\begin{array}{l}\text { Epoxy } \\
\text { coated }\end{array}$ & $B$ \\
\hline Ws & Water reed "Boose" & $\begin{array}{c}\text { Seasone } \\
d\end{array}$ & No & No \\
\hline Wsc & " & $\begin{array}{c}\text { Seasone } \\
d\end{array}$ & $\begin{array}{l}\text { Epoxy } \\
\text { coated }\end{array}$ & No \\
\hline $\mathbf{W g}$ & " & Green & No & No \\
\hline Ws1 & “ & $\begin{array}{c}\text { Seasone } \\
\mathrm{d}\end{array}$ & $\begin{array}{l}\text { Epoxy } \\
\text { coated }\end{array}$ & A \\
\hline Ws2 & " & $\begin{array}{c}\text { Seasone } \\
\mathrm{d}\end{array}$ & $\begin{array}{l}\text { Epoxy } \\
\text { coated }\end{array}$ & $B$ \\
\hline
\end{tabular}




\subsection{Tensile behavior of fibers}

\subsubsection{Sampling}

Five samples are prepared for each fiber type and condition (i.e. exposure and protection). Individual fibers are extracted from each raw materials and the diameter of each fiber is recorded. Four to five individual fibers are straightened between two mounting pads made of grout for each sample. As an exception, one narrow split specimen (i.e. $3 \mathrm{~mm}$ width) of water reed stem "Boose"'" is used and its cross section area is recorded. Dimensions of the mounting pads and the sample length are defined to fit the testing machine's grip dimensions and to avoid slippage of the tested seasoned samples. Different attempts have been tried to determine the suitable embedded fiber length to avoid such slippage. Mounting pads are made of Masterflow $544 \mathrm{M}$ grout, a product of MBT Company. Tensile and compressive strengths -after 28 days- equal 5 and $28 \mathrm{~N} / \mathrm{mm}^{2}$ respectively. Fig (3) shows a photo of group of samples ready for tensile test.

\subsubsection{Test setup}

Upon curing of the grout parts, all samples are installed in the universal testing machine and loaded under displacement controlled routine of fixed value equals $0.1 \mathrm{~mm} / \mathrm{min}$. Fig (4) shows a photo of sample installed in the machine and ready for loading. Using data acquisition system, the load-displacement curve is recoded during testing and finally failure mode for each sample is monitored. Using the initial values of the gage length and the sample's cross-sectional areas, the stress-strain curve is calculated.

Mainly three modes of failures are observed during testing: fiber facture at the middle third, fiber slippage and fiber fracture just behind the mounting pad. In this research work, tensile strength, elongation and modulus of elasticity of the fibers are considered only for fibers/splits fractured at the middle third.

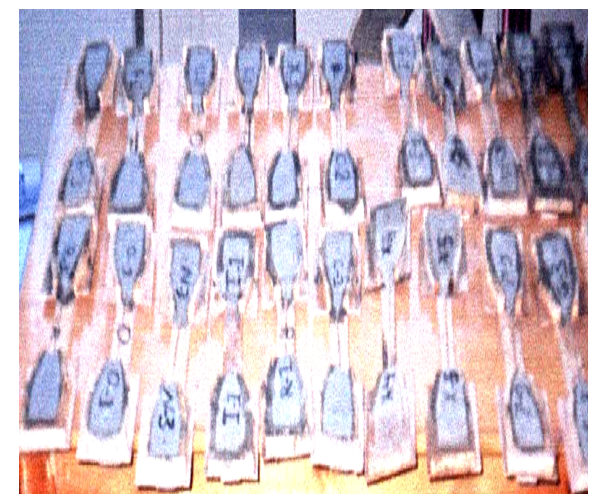

Fig.3 Group of fiber specimens prepared in forms

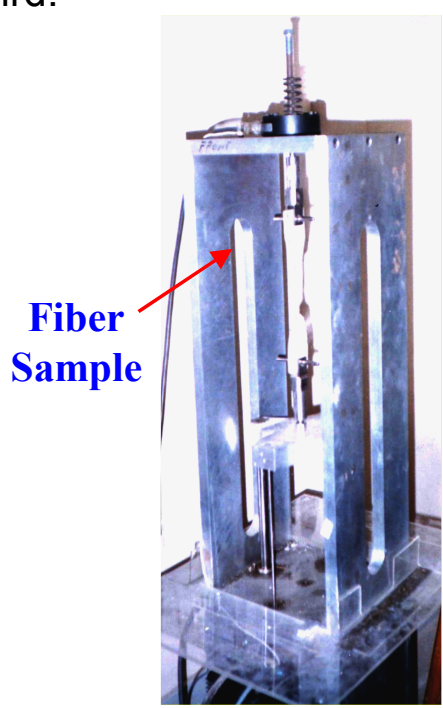

Fig. 4 fiber specimen ready for tensile test 


\subsection{Tensile Behavior of Rebars}

\subsubsection{Tensile test}

\subsubsection{Sampling}

Five samples are prepared for each rebar type and condition (e.g. age). Two mounting pads are prepared for each sample's end to fit the tensile machine grip's dimensions and to avoid/ delay slippage of the tested rebars. Generally, a steel pipe of $25 \mathrm{~mm}$ diameter has been used to form end pad. The gap between the steel pipe and the sample's end is filled with Masterflow 544 grout. To overcome the problem of the recorded slippage, during the primary testing stages, better anchorage scheme (i.e. longer, sanded and steel wire spiraled ends) is provided to the sample's ends along with contracting the cross section of the sample at its middle third length to assure tensile failure in the middle third.

\subsubsection{Test Setup}

Similar to the tested fibers, upon curing of the grout, all samples are installed in the universal testing machine and loaded under displacement controlled routine of fixed value equals $0.5 \mathrm{~mm} / \mathrm{min}$. Fig (5) shows a photo of sample installed in the machine and ready for loading. Similar to the tested fibers, stress-strain curve and the mode of failure of each rebar sample is recorded. As expected, the same three modes of failures, as fibers, are observed during testing. In this research work, tensile strength, elongation and modulus of elasticity of the rebars are considered only for samples fractured at the middle third. However, for rebars which have no case of fracture failure (e.g. green rebars), the maximum strength before slippage and the corresponding elongation are recorded as lower boundaries for strength and ductility. While the initial slope of the stress-strain curve can represent its modulus of elasticity.

\subsubsection{Pull out Test}

\subsubsection{Sampling}

In order to have more comprehensive information of the explored rebars, their pull out behavior is examined. Five seasoned samples are tested under pull out loading. Samples diameter is selected to be very close for all samples to overcome the anchorage length to rebar diameter ratio interference. Each sample has a mounting end similar to that used in tensile test and the other embedded -fully- in a $100 \mathrm{x}$ $100 \mathrm{~mm}$ cross-section and $150 \mathrm{~mm}$ height concrete block. The average compressive strength of concrete block is $22 \mathrm{MPa}$.

Due to their smooth surfaces and volume changes with water, the pull out strength of the unprocessed natural rebars is low. Therefore, slippage mode of failure controls the tensile behavior of the natural rebars as reinforcing elements. To enhance the pull out behavior of these rebars the following points are considered; 
- Use suitable surface coating agent to reduce their water absorption and correspondingly reduces the volume changes beside enhancing their durability. And

- Increase the roughness and the contact surface area of the rebar using sanding technique and/or spiral wire respectively.

Therefore, five unprocessed samples are tested under pullout. In addition, three types of surface treatment are applied to study their effect on the sample's bond strength. Low viscosity local epoxy (i.e. Kemapoxy 104 produced by CMB Company) is applied to all treated samples. For technique (A), of the end anchorage enhancement, sand is applied on the rebar surface before the setting of the epoxy coat. In addition for technique (B), $1 \mathrm{~mm}$ diameter steel wire is spiraled around the end's length and around $10 \mathrm{~mm}$ pins length embedded in a staggered way every $25 \mathrm{~mm}$ of the length.

\subsubsection{Test Setup}

Samples are mounted in the universal machine using special gripping steel end to fix the concrete block end as shown in Fig (6) and each sample is loaded in a similar routine to the rebar's tensile test. Using the rebar's surface area, the pull out strength of each sample is calculated. Although, slippage failure is the mode of concern, any other premature modes of failure (e.g. rebar fracture) can be used as lower boundary for bond strength.

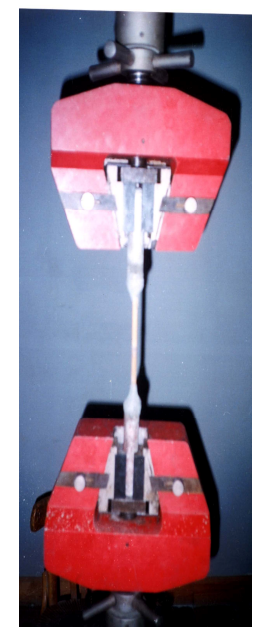

Fig. 5 Rebar specimen ready for tensile test

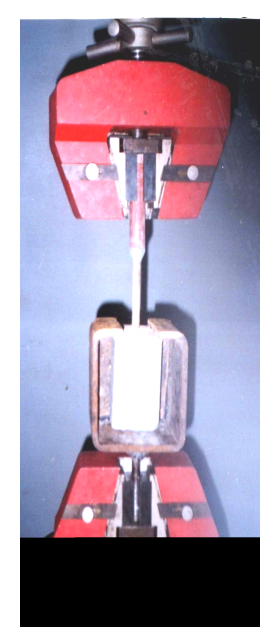

Fig. 6 Rebar specimen ready for pull out test

\section{TEST RESULTS AND DISCUSSION}

\subsection{For Fibers}

Table (6) presents the physical and mechanical properties range for the natural fibers explored in this research. In addition, to represent tensile behavior of each explored natural fiber, the average stress-strain curves of the explored fiber types are presented. 
Fig (7) shows the stress-strain relationships of different samples of the water reed stem "Boose" splits and their average curve. Based on the same idea, the average stress-strain curves of different explored fibers extracted from palm tree are presented in Fig (8). Referring to table (6) and figures (7) and (8), a comparison between the behaviors of different fiber's types can be presented referring to the palm tree ribs "Greed" inner fibers behavior. In this comparison the following remarks can be pointed:

1- Although palm tree ribs inner and outer fibers are coming from the same source, remarkable difference is appeared in their tensile behavior (i.e. strength, modulus and elongation at failure). The outer fibers are stronger, stiffer and less ductile than the inner fibers. On the other hand, the water absorption of the outer fiber is about the half of the inner fiber which provides fairly better insulation for the whole rib.

2- The tensile strengths of, extracted fibers from the palm tree trunk coir "Kheash" and leaves, are closer to the inner fibers while the tensile modulus of elasticity of the leaf is the highest of the three fibers. On the other hand, the water observation of truck coir fibers "Kheash" and the leaf's fibers is higher than that of the ribs inner fibers by about $70 \%$.

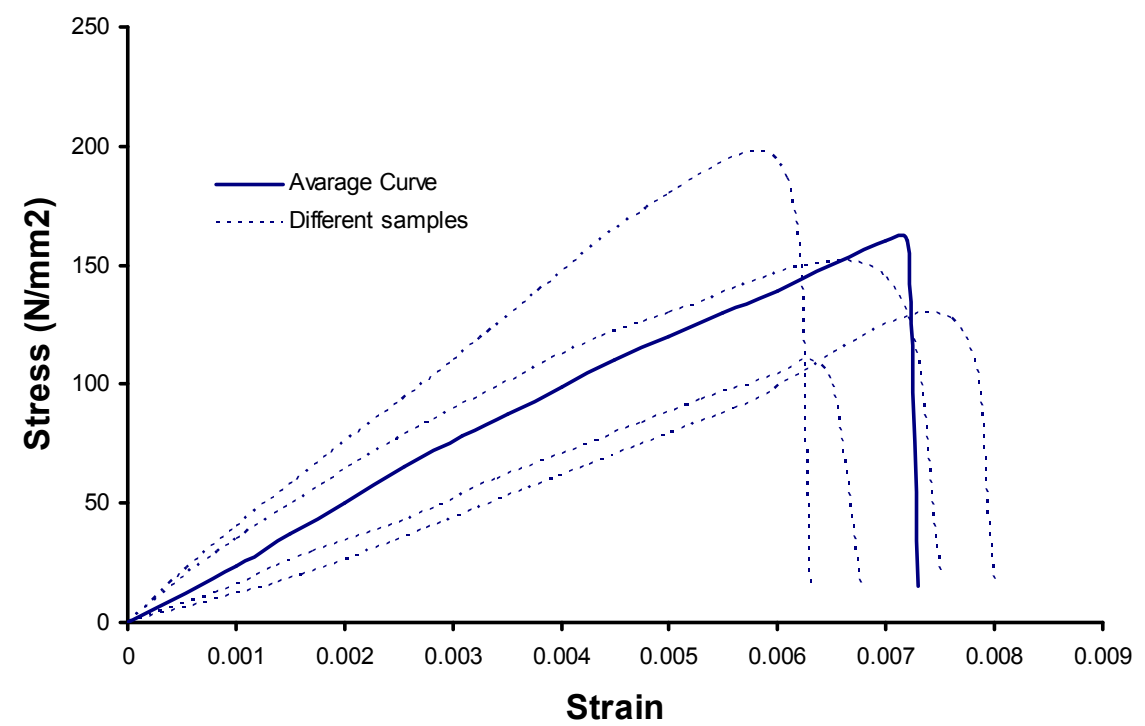

Fig. 7 Stress-strain curves of different samples under tension for seasoned water reed stem (Boose) splits and their average curve 
Table 6. Physical and mechanical properties of different natural fiber samples

\begin{tabular}{|c|c|c|c|c|c|c|c|}
\hline \multirow[b]{2}{*}{ 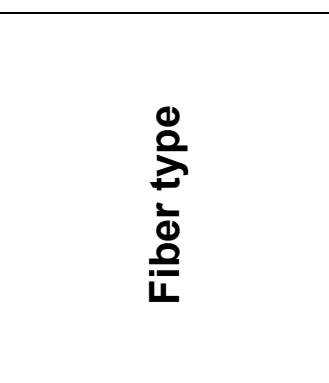 } & \multirow[b]{2}{*}{$\begin{array}{l}\frac{0}{0} \\
\frac{0}{0} \\
\frac{1}{\varepsilon} \\
\text { ஸे }\end{array}$} & \multicolumn{3}{|c|}{$\begin{array}{c}\text { Physical Properties } \\
\text { (just before tensile test) }\end{array}$} & \multicolumn{3}{|c|}{ Mechanical Properties } \\
\hline & & 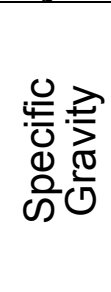 & 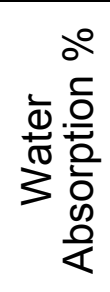 & 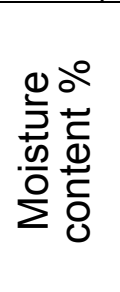 & 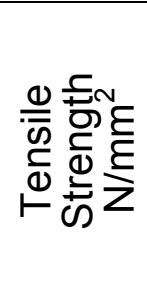 & 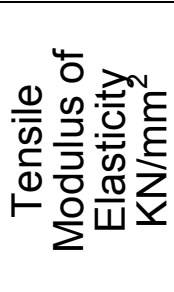 & 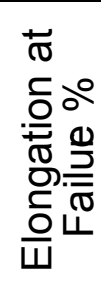 \\
\hline $\begin{array}{l}\text { Palm tree trunk } \\
\text { coir "Kheash" }\end{array}$ & $A$ & 0.75 & 117 & 8.3 & $\begin{array}{l}150- \\
190 \\
\end{array}$ & $6.5-8$ & $2-5$ \\
\hline $\begin{array}{l}\text { Palm tree inner } \\
\text { fiber of ribs } \\
\text { "Greed" }\end{array}$ & B & 0.69 & 71 & 17.3 & $80-180$ & $5-10$ & 2-4 \\
\hline $\begin{array}{l}\text { Palm tree outer } \\
\text { fiber of ribs } \\
\text { "Greed" }\end{array}$ & C & 1.07 & 37 & 11 & $\begin{array}{l}200- \\
480 \\
\end{array}$ & $27-35$ & $\begin{array}{l}0.5- \\
1.0 \\
\end{array}$ \\
\hline Palm tree leaf & D & 0.69 & 124 & 10 & $\begin{array}{l}110- \\
210\end{array}$ & $9-16$ & $\begin{array}{l}1.0- \\
1.8\end{array}$ \\
\hline $\begin{array}{c}\text { Water reed } \\
\text { strips "Boose" }\end{array}$ & $E$ & 0.3 & 76 & 12 & $\begin{array}{l}110- \\
200\end{array}$ & $12-18$ & $\begin{array}{l}0.7- \\
0.9\end{array}$ \\
\hline
\end{tabular}

3- Although, the tensile strength of the water reed stem (Boose) split and water absorption are very close to that of the palm tree ribs inner fiber, their tensile modulus of elasticity and specific gravity values are far away. The specific gravity of the split is very low which make its use as reinforcing elements not easy. While the split's tensile modulus of elasticity is about twice that of the inner fiber.

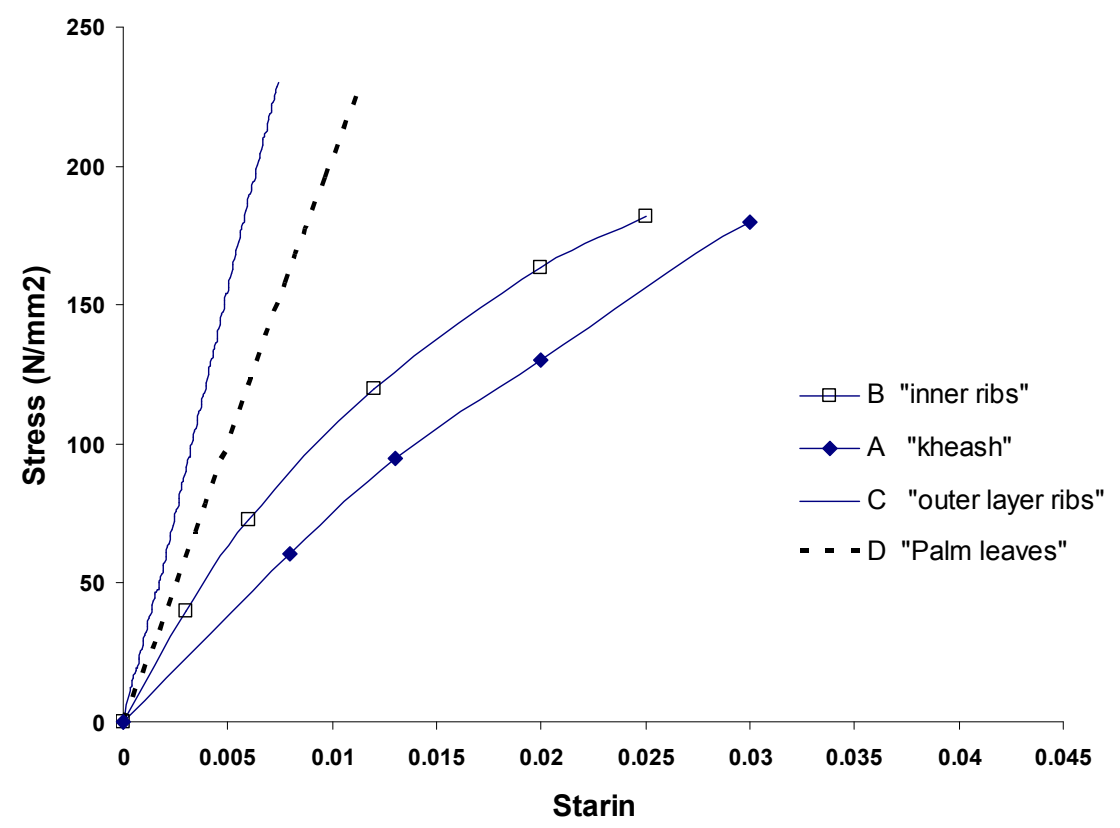

Fig. 8 The average stress-strain curves under tension of different explored fibers extracted from different parts of palm tree 
The effect of coating natural fibers on their water absorption and tensile strength and modulus of elasticity is presented in Figures (9) and (10) for the Kheash and ribs inner fibers respectively. In addition, Figures (9) and (10) show the effect of water and saturated calcium hydroxide solution immersion on the tensile behavior of the unprocessed (i.e. virgin) fibers as well as the coated fibers. In Figures (9) and (10) the effect of the exposure and/or the protection conditions are traced using the ratio of each behavior of the exposed and/or coated fiber and the same property of the standard (unprocessed and unexposed) fiber. Referring to both Figurers (9) and (10), the following remarks can be pointed;

1- Epoxy coating of the studied fibers surface reduces the water absorption by about $35 \%$ and $90 \%$ for Kheash and rib inner fiber respectively. This remarkable difference is due to the high water absorption of Kheash fibers through the fiber's cross section instead of the fiber's surface compared to the rib inner fiber. In addition, epoxy coating increases the tensile modulus of elasticity of the fibers by about $20 \%$. This is due to the binding effect of the epoxy as a matrix for composite material, which increases the modulus of elasticity over the individual fibers.

2- Short- term exposure (i.e. 2 month) in calcium hydroxide solution reduces the tensile strength and modulus for both fibers' types by about $20 \%$ and $30 \%$ respectively. On the other hand, immersion in water for the same period reduces strength and modulus for both fibers' types by about $10 \%$ and $15 \%$ respectively. The water immersion effect on tensile behavior is, most probably, due to the miss of contact with the surrounding grout because of the swelling and drying. This means that about $50 \%$ of the reduction in tensile behavior of the tested fiber -in the short term- with immersion in calcium hydroxide solution can be due to swelling rather than deterioration.

3- For the explored fibers, applying epoxy reduces the effect of immersing natural fibers in both water and calcium hydroxide solution. This is, mainly, due to the water absorption reduction with using epoxy coating. Reduction of tensile strength and modulus for epoxy-coated fibers does not exceed $6 \%$ and $10 \%$ respectively with the immersion in calcium hydroxide solution. While reduction of tensile strength and modulus for epoxy coated fibers is negligible with the short-term immersion in water. 


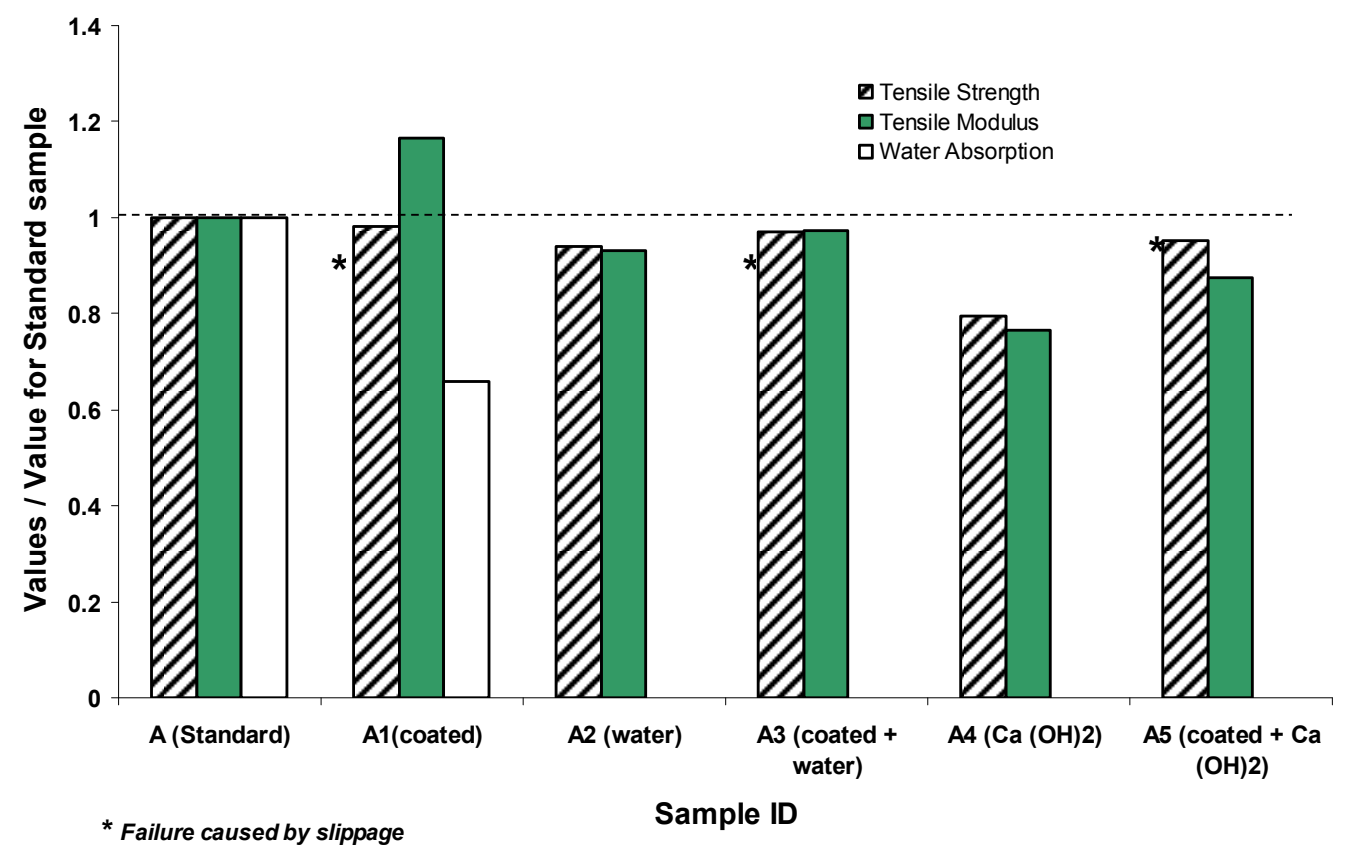

Fig. 9 Behavior of different samples of Palm tree trunk coir "Kheash" fibers after the application of different protection/exposure conditions

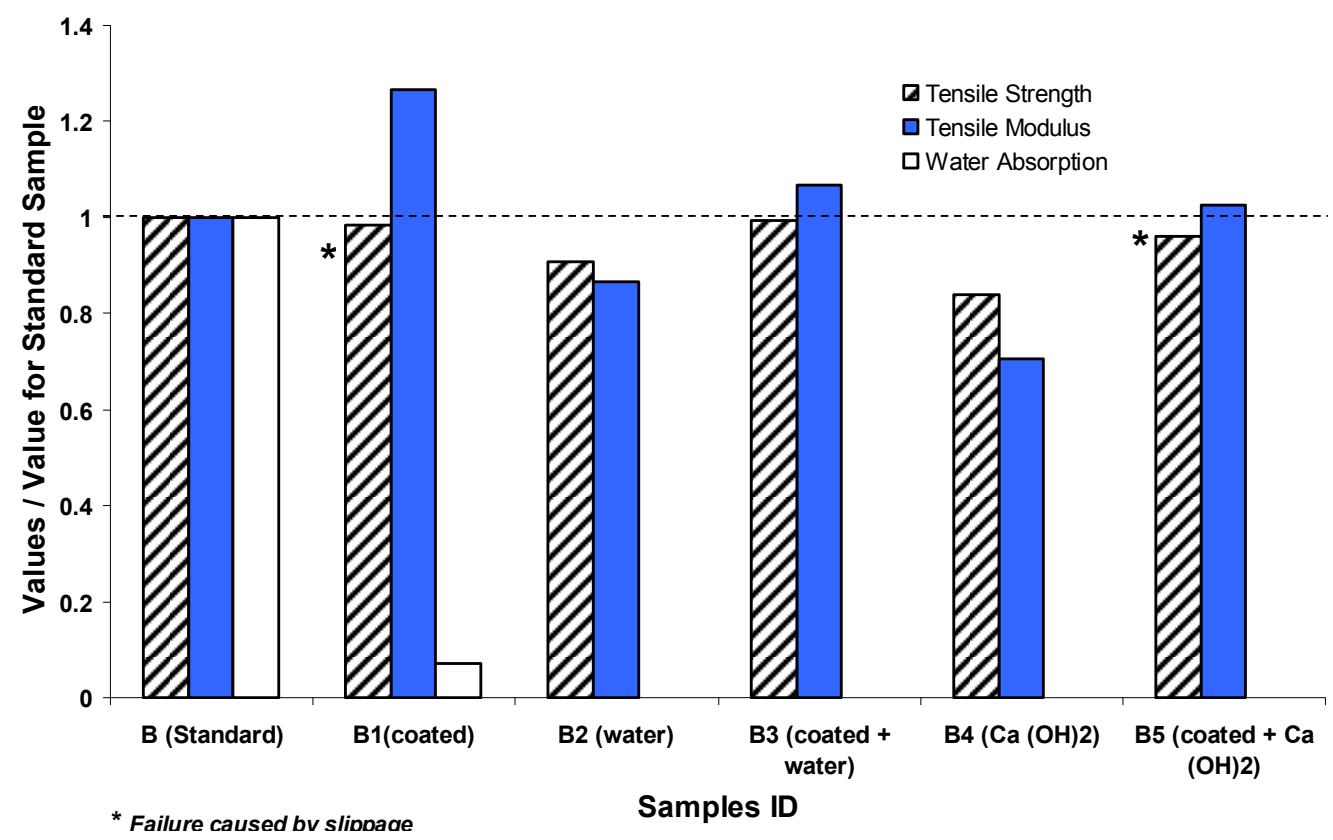

Fig. 10 Behavior of different samples of palm tree inner fibers of ribs "Greed" after the application of different protection/exposure conditions

\subsection{For Rebars}

Table (7) shows the physical and mechanical behaviors of the whole palm tree rib "Greed" and water reed stem rebars in different conditions. In addition, the average stress-stain curves of the unprocessed seasoned rebars are also presented in Fig (11). On the other hand, the bond strengths of these two types of natural rebars - in their seasoned condition- are presented in Fig (12). In this figure, the effect using 
different techniques for protection and enhancement on the bond strength is also presented.

Referring to Table (7) and Figures (11) and (12), the following remarks are pointed:

1- Seasoned whole palm tree rib "Greed" rebar is stronger and stiffer than the seasoned water reed stem "Boose" rebar.

2- Although the majority of the green and epoxy coated rebars -of both typesfailed by slippage, just before slippage their maximum tensile stresses reach 90-60 \% respectively of the unprocessed seasoned rebars. On the other hand, applying epoxy coating to the rebars surfaces reduce their bond strength due to the smooth surface of the bars, while the water absorption reduces dramatically leading to enhancement of their volume changes in water and durability in aggressive media.

3- Using epoxy coating along with either sanding (Technique A) or sanding and spiral wires (Technique B) increases the rebar's bond strength. Using technique $A$ increases the bond strength with ratios ranged between 40 to $60 \%$ for Boose and Greed rebars respectively, while technique B increases the bond strength with about $100 \%$ - on the average- for both types of rebars.

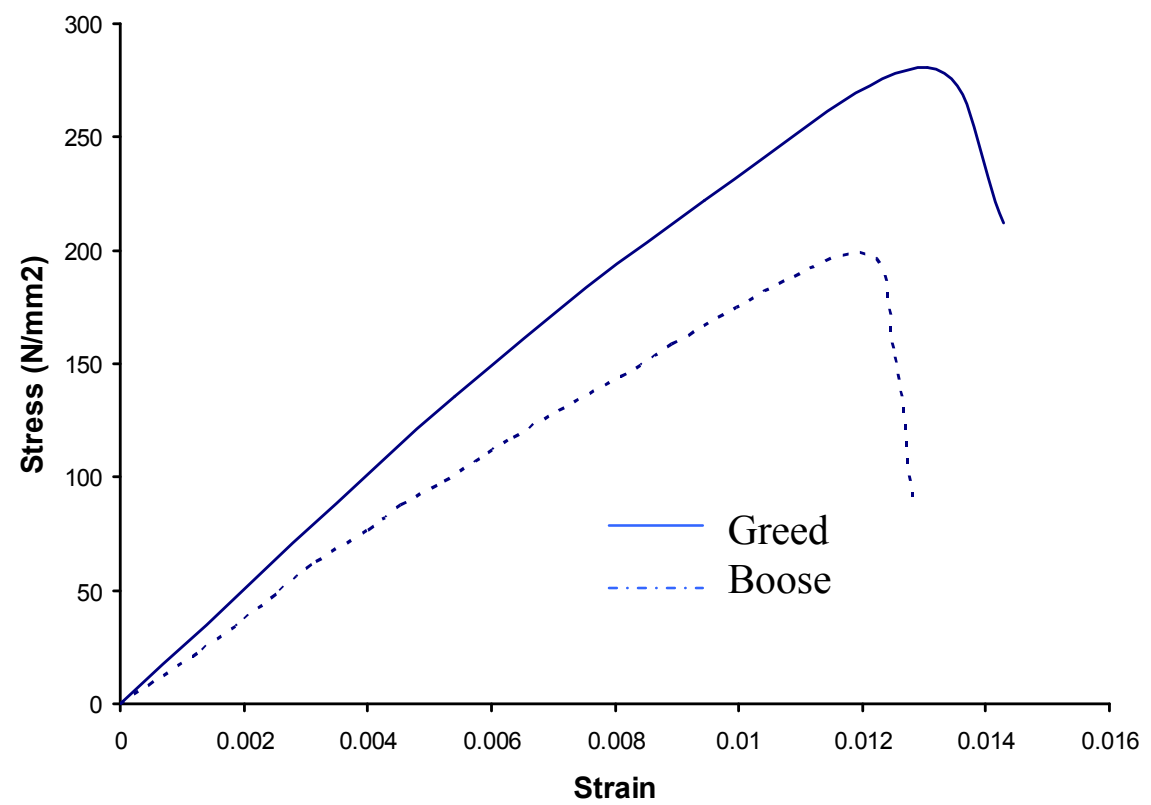

Fig.11 The average stress-strain curves of seasoned samples of palm tree whole ribs "Greed" and water reed stem "Boose" under tension

Table 7. Physical and mechanical properties of different natural rebar samples 


\begin{tabular}{|c|c|c|c|c|c|c|c|}
\hline \multirow[b]{2}{*}{ 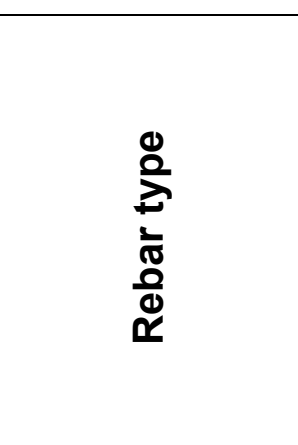 } & \multirow[b]{2}{*}{$\frac{\frac{0}{0}}{\frac{0}{0}}$} & \multicolumn{3}{|c|}{$\begin{array}{c}\text { Physical Properties } \\
\text { (just before tensile } \\
\text { test) }\end{array}$} & \multicolumn{3}{|c|}{ Mechanical Properties } \\
\hline & & 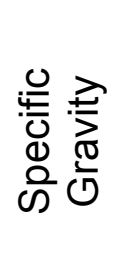 & 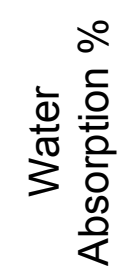 & 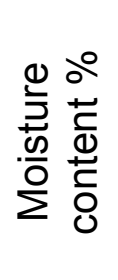 & 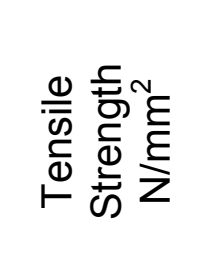 & 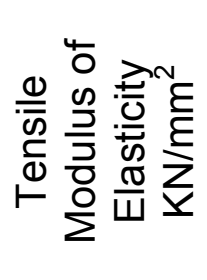 & 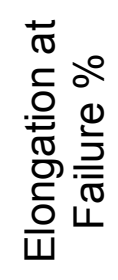 \\
\hline $\begin{array}{c}\text { Seasoned } \\
\text { Whole Palm } \\
\text { tree ribs } \\
\text { "Greed " } \\
\end{array}$ & Rs & 0.95 & $55-70$ & 9.2 & $180-325$ & $12-22$ & $1-3$ \\
\hline $\begin{array}{l}\text { Seasoned } \\
\text { Coated Whole } \\
\text { Palm tree ribs } \\
\text { "Greed " }\end{array}$ & Rsc & 0.98 & 4.1 & ------ & $165-205^{*}$ & $10-17$ & $1.5-5$ \\
\hline $\begin{array}{l}\text { Green Whole } \\
\text { Palm tree ribs } \\
\text { "Greed " }\end{array}$ & $\mathbf{R g}$ & 1.1 & 33 & 22 & $190-230$ * & $5-10$ & $2-4$ \\
\hline $\begin{array}{l}\text { Seasoned } \\
\text { Water reed } \\
\text { "Boose" }\end{array}$ & Ws & 0.32 & 77 & 15.6 & $190-240$ & $7.4-9.0$ & $1.5-2$ \\
\hline $\begin{array}{l}\text { Seasoned } \\
\text { Coated Water } \\
\text { reed "Boose" }\end{array}$ & Wsc & 0.35 & 7.3 & ------- & $150-220$ * & $8.2-13.1$ & $\begin{array}{l}1.5- \\
2.8\end{array}$ \\
\hline $\begin{array}{l}\text { Green Water } \\
\text { reed "Boose" }\end{array}$ & $\mathbf{W g}$ & 0.55 & 45 & 37 & $100-140$ * & $4-6.8$ & $2.7-4$ \\
\hline
\end{tabular}

* All samples failed by slippage
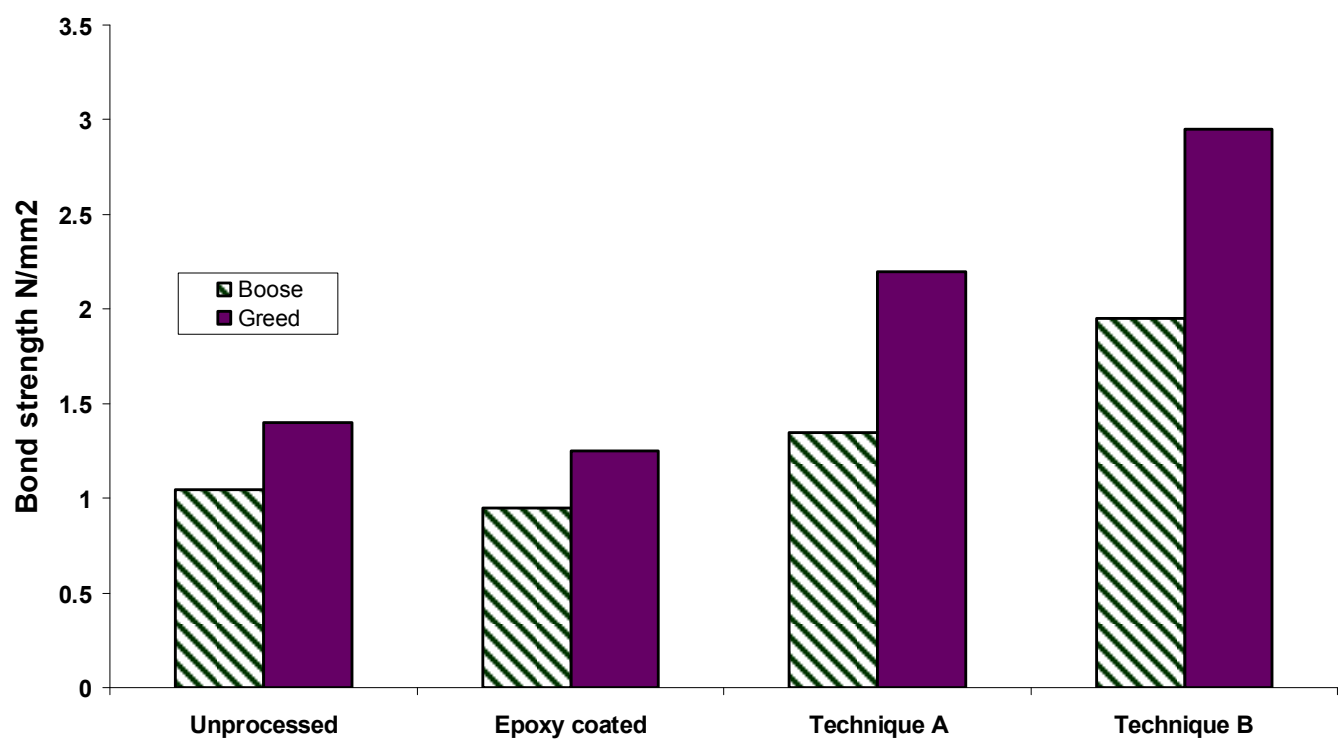

Natural rebar condition

Fig.12 Bond strength of different rebars of palm tree whole ribs "Greed" and water reed stem "Boose" in different enhancement conditions 


\section{CONCLUSIONS}

1- Many of the studied agricultural residues have promising tensile strength, which is high enough to be used as reinforced elements for wide spectrum of construction applications. However, the tensile behavior of some of the selected samples of fibers and rebars show wide variation. This is due to their nature as natural materials, which may be affected by various factors such as their cultivation and exposure history.

2- The explored agricultural residues have tensile strength values, which ranged between $40-130 \%$ of the ultimate tensile strength of mild steel. However, the maximum tensile modulus of elasticity and elongation at failure values reach only $20 \%$ and $25 \%$, of the values for the mild steel, respectively. Though, construction materials reinforced with these natural materials (e.g. natural fiber reinforced concrete) will have good tensile capacity and enhanced crack control and toughness but with less extend of this enhancement to stiffness and ductility.

3- During the applied short-term exposure period, the average reduction of the explored fiber's tensile strengths reaches $20 \%$ and $10 \%$ for immersion in calcium hydroxide solution and water respectively. While during the same exposure conditions the average reduction of the same fiber's tensile modulus of elasticity reaches $30 \%$ and $15 \%$ for immersion in calcium hydroxide solution and water respectively.

4- Even though, epoxy coating reduces the bond strength of the explored natural rebars and accordingly their tensile capacity, sample's water absorption are dramatically reduced by range between 40 to $90 \%$ of its original value. The water absorption reduction overcome/delay the degradation criteria (i.e. fermentation and deterioration) beside controlling fiber's volume changes, with the exposure to surrounding moisture

5- The age of the explored agricultural materials -after cutting- and their corresponding moisture contents affects their tensile capacity. Within this scope of study, it is fond that the more the moisture content (i.e. green samples) the less bond strength which controls the failure under tension in this case.

6- Bond strength of the tested agricultural rebars are enhanced by about $60 \%$ with epoxy coating and sanding their ends and by about $100 \%$ with adding spiraled steel wires around embedded pins every $25 \mathrm{~mm}$ of the rebar end length.

\section{POINTS FOR FURTHER STUDY}

Based on this investigation, a huge number of points need to be clarified -in the further study- to have a reliable data base of the promising agricultural residues as reinforcing elements. On the other hand, there is a leak of confidence of agricultural residue's behavior under service conditions compared to the long experience with 
using other inorganic materials (e.g. steel). The followings are among many points, which need further study;

1- Comprehensive study needs to be applied on different promising local agricultural residues to ensure a predictable behavior under different service conditions.

2- Long-term durability needs a neat study for the explored agricultural residues behavior under different exposure conditions.

3- Efficient and economic methods are required to be investigated for protection and enhancing techniques of agricultural reinforcing materials.

4- The possible combinations of the explored agricultural residues and different available binding materials need to be studied to have the suitable construction materials with higher capacity and more durable behavior.

\section{REFERENCES}

1. Al-Ashker, N.H.A. (1996) anew Type Palm-Originated Date Cluster Stem Fibers For Reinforced Concrete, M. Sc. Thesis, Structural Department of Civil Engineering, Faculty of Engineering, Cairo University, 19968.

2. Coutts, R.S.P. (1983) flax fibers as a reinforcement in cement mortars Int. J. Cem. Comp. Lightweight Concr. 5 (4), 257-262.

3. El-Mously, H.I. (1998) The date palm: the princess of a sustainable future. INES Newsletter N. 23.

4. El-Mously, H.I. (1997) The rediscovery of local raw materials: new opportunities for developing countries. Industry and Environment, Vol. 20, No.1-2, January-June, 1997.

5. El-Mously, H.I., Zamzam M.A. and Ibrahim N.H.(1995) Mechanical properties of date palm leaves' midrib (DPLM) in relation to its utilization as a substitute for solid wood. Poster presentation, IUFRO XX World Congress, Tampere, Finland, 6-12 August 1995.

6. El-Shabasy A.B. And H.I. El-Mously. Study of the variation of tensile strength across the cross-section of date palm leaves' midrib. Proceedings of the $5^{\text {th }}$ European Conference on Advanced Materials and Processes and Applications. Vol. 4, Characterization and production/Design, Maastricht, 2123 April, 1997.

7. Gram, H.E., (1983) Durability of natural fibers in concrete. Research Report 1, Swedish Cement and Concrete Research Institute, Stockholm, p. 255.

8. Sharkawi, A. M. and Showaib, E. A. (2004) Proposed program for studying the use of local agricultural residual materials for reinforcing low cost construction materials. Proceedings of the $5^{\text {th }}$ International Conference on the Role of Engineering Towards a Better Environment (RETBE 04), Alexandria, Egypt, December 2004

9. Shuen. C. W. et al. (1992) Relationships between anatomical characteristics and permeability properties in Taiwan grown bamboo species. Bamboo and its uses. International symposium on industrial use of bamboo, Beijing, China, Dec., 1992.

10.Swamy, R.N. (ed.) (1984) New Reinforced Concretes, Surrey University Press, Blackie\& Sons Ltd. 
11. Youseef, M.A.R. (1976) Bamboo as a substitute for steel reinforcement in structural concrete. New Horizon in Construction Materials, Vol.1, H.Y. Fang (ed.), Envo. Publishing Co., Lehigh Valley, U.S.A., 525-54.

12. Youseef, M.A.R. (1968) Bamboo as a substitute for steel reinforcement in structural concrete. Non-Metallic Reinforcement for Concrete Structural Elements, M. Sc. Thesis, Structural Department of Civil Engineering, Faculty of Engineering, Cairo University, Sept. 1968. 